\title{
Stimulus generation, ratings, phoneme counts, and group classifications for 696 famous people by British adults over 40 years of age
}

\author{
JAMES H. SMITH-SPARK \\ London South Bank University, London, England \\ VIV MOORE and TIM VALENTINE \\ University of London, London, England \\ and \\ SUSAN M. SHERMAN \\ University of Sheffield, Sheffield, England
}

\begin{abstract}
Matching stimuli across a range of influencing variables is no less important for studies of face recognition than it is for those of word processing. Whereas a number of corpora exist to allow experimenters to select a carefully controlled set of word stimuli, similar databases for famous faces do not exist. This article, therefore, provides researchers in the area of face recognition with a useful resource on which to base their stimulus selection. In the first phase of the investigation, British adults over 40 years of age were requested to generate the names of famous people (or celebrities) that they thought they would recognize and to write these down. The most frequently named celebrities were then rated by adults from the same age population for familiarity, distinctiveness, and age of acquisition. The result is a database of 696 famous people, with an indication of their relative eminence in the public consciousness and rated for these important variables. Phoneme counts are also provided for each famous person, together with family name frequency counts in the general population, where available. Materials and links may be accessed at www.psychonomic.org/archive.
\end{abstract}

A major concern in psychological research is to match stimuli across as many variables as possible while manipulating only the experimental variable. Ready-made databases containing the information that allows such matching and manipulation are, thus, particularly useful to researchers across a number of fields. They have proved their worth in such domains as lexical processing (e.g., the CELEX Database of Baayen, Piepenbrock, \& van Rijn, 1993; Bird, Franklin, \& Howard, 2001; Coltheart, 1981; Cortese \& Fugett, 2004; Gilhooly \& Logie, 1980a, 1980b; Morrison, Chappell, \& Ellis, 1997; Paivio, Yuille, \& Madigan, 1968; Spreen \& Schulz, 1966; Stuart, Dixon, Masterson, \& Gray, 2003) and picture and object processing (Alario \& Ferrand, 1999; Carroll \& White, 1973; Cycowicz, Friedman, Rothstein, \& Snodgrass, 1997; Masterson

This research was supported by Economic and Social Science Research Council Grant R000429624208 awarded to V.M. and T.V. We thank all the participants who kindly contributed their time and effort to the work reported in this article. We are grateful to Marc Brysbaert and Patrick Bonin for their helpful comments on an earlier draft of the manuscript. S. M. S. also thanks Sara Howard of the Department of Human Communication Sciences at the University of Sheffield for her useful advice about phonetics. Correspondence concerning this article should be addressed to J. H. Smith-Spark, Department of Psychology, London South Bank University, 103 Borough Road, London SE1 0AA, England (e-mail: smithspj@1sbu.ac.uk).
\& Druks, 1998; Snodgrass \& Vanderwart, 1980; Szekely et al., 2004).

Similarly, the speed of face and name processing is also dependent on a number of influential variables. Famous faces are notoriously difficult to name (for a review, see Valentine, Brennen, \& Brédart 1996). It is, therefore, also of great importance for face- and name-processing research to ensure that the stimuli are well known to participants and that the target items are well matched across a range of variables known to influence response times. The data in this article will help researchers to match and manipulate experimentally the faces of a large number of famous people for familiarity (cumulative frequency), facial distinctiveness, age of acquisition (henceforth, AoA), surname frequency, and number of phonemes.

It is obvious that the degree of familiarity that a participant has with a particular famous person will have a strong influence on processing speed. The familiarity, or cumulative frequency, ${ }^{1}$ effect for faces has been reported by several researchers (e.g., Lewis, 1999; Moore \& Valentine, 1998; Rendell, Castel, \& Craik, 2005). In the present article, the participants were instructed to base their judgments on the number of times they had seen, or been reminded of, each celebrity in the course of their lives. The rating was to include auditory, visual, or verbal encounters with the famous person in different media and also any face-to-face encounters that they may have had. Brédart 
(1993) has demonstrated a positive relationship between rated familiarity of celebrity names and naming accuracy. With respect to word processing, a recent connectionist report accused AoA studies of not correctly controlling the count of word frequency (Zevin \& Seidenberg, 2002). In this article, Zevin and Seidenberg stressed the importance of rated familiarity as a measure of word frequency and cited Gernsbacher (1984) in support of their position. Gernsbacher proposed that rated familiarity is a more sensitive measure of frequency differences than are word frequency counts obtained from published corpora.

The visual complexity of drawn objects has been reported to be a powerful predictor of processing speed on a number of object-processing tasks (e.g., Vitkovitch \& Tyrrell, 1995; but see Alario et al., 2004, for a review of objectnaming studies). This is also true of the structural similarity of the categories from which the stimuli are drawn. Humphreys, Riddoch, and Quinlan (1988) showed that the structural similarity of object categories affected naming latencies. They demonstrated that objects from structurally dissimilar categories in which the exemplars are visually dissimilar from each other (e.g., furniture) are, under some circumstances, named more quickly than objects from structurally similar categories (e.g., fruits, animals). The similarity of these effects to the facial distinctiveness effect has been explained in terms of a "multidimensional face space model" by Valentine (1991). According to Valentine's model, typical faces are hard to distinguish because they are represented in a densely populated area at the center of a multidimensional space. Proximity makes these representations easy to confuse. Conversely, distinctive faces are located in a sparsely populated area on the periphery of this multidimensional space. Here, there is little overlap and, thus, less similarity across faces. A distinctiveness effect for the recognition of faces has been much reported in the psychological literature, such that distinctive faces are responded to more accurately and more quickly than less distinctive or more typical ones (e.g., Sarno \& Alley, 1997; Valentine, 1991; Valentine \& Bruce, 1986). Sommer, Heinz, Leuthold, Matt, and Schweinberger (1995) demonstrated that the distinctiveness ratings provided by their experimental participants correlated significantly with both their predicted and the actual recognition of faces. Clearly, the similarity of structure of an object (see Moore, SmithSpark, \& Valentine, 2004) or the typicality of a face would complicate accurate identification, rather than facilitate it. Distinctiveness ratings are employed in this article to ensure that any visual similarities will be identified and weighted appropriately.

Valentine, Brédart, Lawson, and Ward (1991) explored whether the effect of the frequency of surnames in the population would influence recognition of famous people's names. They found that the effect of surname frequency was analogous to the effect of word frequency in tasks that did not require recognition of the individual (e.g., reading a name aloud). They found that high-frequency surnames were responded to more rapidly. However, the effect of surname frequency was analogous to the effect of facial distinctiveness in tasks that did require recognition of the individual (e.g., determining whether or not a name was familiar). When an individual was recognized, the resulting advantage was in favor of low-frequency (or distinctive) surnames. The influence of surname frequency is not restricted to the processing of printed word names. Valentine and Moore (1995) investigated the influence of surname frequency on face naming. The authors manipulated surname frequency in a factorial design, teaching high- and low-frequency surnames (and controlling for other relevant variables) to be associated with pictures of unfamiliar faces (controlling for facial distinctiveness and other visual attributes). Their participants were presented with faces and were asked to name them, producing the surname that they had been trained to associate with each face. For example, Face A was paired with Name A (low frequency; e.g., Babich). Other participants were given Face A paired with Name B (high frequency; e.g., Smith). The effect of surname frequency was found to be analogous to the effect of word frequency on object naming, with items that had been allocated high-frequency surnames being named more quickly and more accurately than those that had been given low-frequency surnames. However, when famous faces were named, there was an advantage for participants in producing low-frequency surnames. Valentine and Moore explained these results in terms of differences in the underlying nature of surname frequency and word frequency - that is to say, in terms of the differences in the task demands between the naming of objects (which requires naming a token; e.g., a chair) and the naming of a person (which requires the production of a token marker; e.g., a unique individual, identifying John Smith).

Where available, surname frequencies are reported (Moore \& Valentine, 1993) for each famous person. The measure of frequency used in this article represents a count of surname frequencies taken from the 1989 South Manchester telephone directory. This measure has produced high correlations with samples drawn from other telephone directories. For example, between South Manchester and Durham, $r=.87$; between North Manchester and South Manchester, $r=.94$; and between South Manchester and Exeter, $r=.91$ (Moore \& Valentine, 1993). There were an estimated 261,105 nonbusiness surnames in the directory. The frequency count was calculated using $\log (x+1)$ of the number of occurrences of the surname per 100,000 entries.

Surname frequency is not directly analogous to word frequency. For example, a very large number of people in the U.K. share the surname Smith, resulting in the name's having a high surname frequency. The number of times the surname Smith is experienced will be affected by the number of people who have the name and how frequently they have been encountered (either personally or in the media). However, if naming a famous face is assumed to require access to a representation of a full name that, in most cases, is unique to an individual, a better analogy to word frequency would be the familiarity of each celebrity, as described previously. 
An increasing number of studies have demonstrated that AoA is an important predictor of the speed of lexical processing. People are faster to name pictures with names learned early in life than to name pictures with lateracquired names. This effect has been demonstrated across a range of languages, such as Dutch (Brysbaert, Lange, \& Van Wijnendaele, 2000), English (Morrison, Ellis, \& Quinlan, 1992; Morrison \& Ellis, 1995; Turner, Valentine, \& Ellis, 1998), French (e.g., Bonin, Chalard, Méot, \& Fayol, 2002), Icelandic (Pind \& Tryggvadóttir, 2002), and Spanish (Cuetos, Ellis, \& Alvarez, 1999). The effects of AoA are not confined to lexical processing alone. Recently, it has been reported that AoA significantly affected the speed of perceptual classification of object pictures (Moore et al., 2004). Moreover, the age at which a celebrity was first encountered has also been demonstrated to affect the time taken to name their faces, read their names aloud, and decide whether or not a face or name is familiar (Moore \& Valentine, 1998, 1999). The participants in the present study were, thus, required to rate the stimuli on AoA by estimating when in life they had first encountered each famous person.

In addition to the well-documented effects of word frequency and AoA on naming latencies, there is also evidence to suggest that word length is important, both in English (e.g., Klapp, Anderson, \& Berrian, 1973; Morrison et al., 1992) and, cross-linguistically, in Dutch (Meyer, Roelofs, \& Levelt, 2003), Italian (Barca, Burani, $\&$ Arduino, 2002), and French (Ferrand \& New, 2003). ${ }^{2}$ One measure of word length is the number of phonemes in a word (e.g., Cuetos et al., 1999). In a study investigating object picture naming, Morrison et al. (1992, Experiment 1) found that participants took longer to name pictures whose names contained more phonemes than those whose names contained fewer phonemes. Therefore, in order to be able to match stimuli on as many relevant variables as possible, a phoneme count for the famous names has been included.

The phoneme counts presented in this article are based on a model of spoken British English known as BBC English (Jones, 1997), which can be thought of as the typical pronunciation used by newscasters and other professional speakers. Different regional accents might, thus, give rise to different phoneme counts than those presented here.

There are many potential uses for these phoneme counts, and with this in mind, the counts have been broken down into the constituent parts of each name (first name, second name, etc.). The natural effect of this is that phonetic phenomena such as elision, whereby a preceding word might affect the pronunciation of the following word, are not reflected in the counts. In the same spirit, where different pronunciations are possible, the fullest transcription is provided, together with notes denoting this fact, unless the shorter version is considered to be more commonly used. The motivation for this is that in an experimental setting, careful speech is more likely than casual speech; however, the extensive notes will enable users to adapt the counts for their particular purposes. ${ }^{3}$
As well as providing an indication of how well known a celebrity is to members of the general public over 40 years of age, information on the semantic categorization of famous people into occupations, such as politicians, musicians, and film stars, is also provided in this article. In some small way, the database may also provide a document of the sociocultural and historical knowledge and experiences of British adults over the past 80 years.

The data collection took place in two phases. The first was an initial name generation phase, in which the bestknown (or most frequently generated) famous people were uncovered by a large-scale data collection exercise. There then followed a ratings phase, in which the most frequently named celebrities were rated for AoA, familiarity, and facial distinctiveness. It is to the generation phase that this article will now turn.

\section{PHASE 1 Name Generation}

For a database to have utility as a research tool, it is salient that the items contained in it should be well known to the target population from which participants will be drawn. Rizzo, Venneri, and Papagno (2002) have collected normative data on 50 famous people as the basis of a neurological test, collecting data on semantic information. However, they did not collect ratings from their participants, nor did they ask their participants to generate the celebrities themselves. With this consideration in mind, the first phase in the construction of the database involved finding out which famous people were known by a reasonably high proportion of the target population-namely, British adults 40 years of age and over. A large group of participants were requested to write down the names of famous people whose faces they believed they would recognize. It was emphasized that the generation of names should be done on the basis of memory alone and without recourse to any reference book. Decades from 1920 to 2003 and categories of fame (e.g., politics, film, and sports) were printed in the booklet. The categories were chosen by the authors to encompass as many fields of fame pertinent to the participants' population as possible. These were intended to be aides mémoires, not enclosed categories, to help participants structure their recall. The dating of stimuli from the 1920s onward should mean that photographic images are available for any person so generated. The number of times a name was generated was recorded as a frequency count. From this, the famous people best known to the participants (or at the very least, those that sprang most easily to mind from each of the given categories) were determined and entered as stimuli in the subsequent stage of the investigation.

\section{Method}

\section{Participants}

All the participants were U.K. citizens, with English as their first language, and were over 40 years of age. The majority were recruited from advertisements placed in a publication local to the Canterbury area and were paid $£ 1$ for taking part. Other participants were re- 
cruited via posters placed around the University of Kent campus and features on the research that appeared in the University staff newsletter and on local radio. Participants were also recruited via the Saga publication (a national magazine for the over-50s) and Sesame (the Open University newspaper). Some 400 participants were recruited from these sources, with 182 respondents completing and returning the name generation sheet. The age of the participants ranged from 40 to 91 years, with a mean age of 61.37 years $(S D=11.76, S E M=$ 0.91). Of those participants who followed the instructions to write down both their gender and age, there were 105 female respondents (mean age $=59.78, S D=11.85, S E M=1.16$ ) and 50 male respondents (mean age $=62.94, S D=12.08, S E M=1.71)$.

\section{Materials}

A 16-page name generation booklet, an instruction sheet, and a prepaid envelope to return the completed form were posted to each participant.

\section{Design}

The name generation sheet was split into occupations (or semantic categories) to aid recall, and the names of these categories are presented in Table 1. Each category was subdivided into decades dated from 1920-1930 up to 1990-the present day.

\section{Procedure}

The participants were instructed to think of people in each category and then to try to estimate when they had first become aware of that person. The participants were advised that the interest of the study lay in their personal judgment, not an historical entry of the famous person's "dates." It was emphasized that the decades were presented only as another cue to recall and that they need not worry over the accuracy of their estimations, since it was the names that were most important. The participants were requested to write down, on the back of the sheet, any other names that came to mind but that did not readily fit into the categories provided. All the names so generated were entered into a spreadsheet. A frequency count accompanied each of the names to indicate how many participants had written down that particular famous person. For these names and the number of times they were generated, see the online Archive of Norms, Stimuli, and Data.

\section{Results and Discussion}

There were wide differences between the participants in the number of names generated. Some participants named just a few, extremely salient famous people, whereas oth- ers named more than 100 people each. Roughly 4,200 names were generated overall. Time constraints and the need to retain the goodwill of the participant group meant that it was necessary to impose a limit on the number of celebrities for which ratings would be collected. It was decided that the names of famous people generated 10 or more times would be subjected to the more detailed data collection. The online Archive shows all the famous people named by 10 or more participants in the experiment, ${ }^{4}$ giving a total of 696 celebrities. Where a famous person was placed in more than one category, the most frequently chosen category is reported. Other than recording the names and their frequency count, no further data collection was carried out on the remaining famous people named fewer than 10 times.

\section{PHASE 2 Ratings}

As discussed previously, it is important to control for a number of variables known to influence processing speed when designing experiments. Tasks involving the collection of responses to names or faces of celebrities are no exception. Ratings on three scales were collected for all the celebrities named 10 or more times, using Moore's (1998) method. Each famous person was rated for their AoA, familiarity, and facial distinctiveness by at least 20 participants. ${ }^{5}$ These variables were selected due to their strong influence on face-processing tasks.

\section{Method}

\section{Participants}

All the participants were over 40 years of age, many of whom had taken part in the name generation study. One hundred seventyfive question sheets were posted to the participants. Only six of the returned sheets were omitted from coding, due to comprehension difficulties, leaving the data from 149 participants to be coded. In total, 100 females and 48 males $^{6}$ returned the sheets (mean age $=$ $61.76, S D=12.56, S E M=1.03$; range, $40-88$ years). The participants were divided semirandomly across seven groups, with each group receiving a sheet with a different set of celebrity names. The composition of each group is summarized in Table 2. A one-way

Table 1

Semantic Categories Used to Aid Name Generation in Phase 1

\begin{tabular}{ll}
\hline 1. Adventurers/explorers/pioneers & 16. Prime ministers \\
2. Authors/artists/poets & 17. Racing drivers \\
3. Athletes & 18. [U.K.] royal family \\
4. Chancellors of Germany & 19. Rugby players \\
5. Children's TV presenters & 20. Scientists \\
6. Comedians/light entertainers & 21. Singers/musicians \\
7. Cricket players & 22. Snooker/billiards players \\
8. Criminals & 23. Speakers of the House of Commons \\
9. Film stars & 24. Tennis players \\
10. Footballers & 25. Tycoons/millionaires \\
11. French presidents & 26. U.S. presidents \\
12. Ice skaters & 27. Union leaders \\
13. Media personalities & 28. Victims \\
14. News presenters & 29. World leaders \\
15. Politicians & 30. World military \\
\hline Note-The categories are numbered for use in conjunction with the database.
\end{tabular}


Table 2

Mean Group Ages Providing an A Priori Rating

\begin{tabular}{cccccc}
\hline Form & $n$ & Gender & Mean Age & $S D$ & SEM \\
\hline A & 22 & $12: 10$ & 59.09 & 12.41 & 2.65 \\
B & 20 & $12: 8$ & 61.20 & 12.01 & 2.69 \\
C & 20 & $17: 3$ & 62.25 & 10.86 & 2.43 \\
D & 21 & $15: 6$ & 62.76 & 12.50 & 2.73 \\
E & 23 & $14: 8^{7}$ & 61.78 & 13.82 & 2.88 \\
F & 20 & $13: 7$ & 57.80 & 11.13 & 2.49 \\
G & 23 & $17: 6$ & 66.87 & 14.07 & 2.93 \\
\hline
\end{tabular}

Note-Gender, gender ratio (females:males).

ANOVA showed there to be no significant difference between the groups in their mean age $[F(6,142)=1.173, p=.324]$.

\section{Materials}

A score sheet with instructions and a prepaid envelope were posted to each of the participants.

\section{Design}

The score sheets were created using the frequency count data obtained from Phase 1 . Those named 10 or more times were included in the ratings sheets. The names were split into groups of approximately 100 , to prevent fatigue or boredom with the task. There were seven different versions of the sheet (comprising different names), with 25 participants receiving one of the seven sheets. The participants were allotted different versions of the sheet in such a way as to ensure that the mean age of each of the seven groups was kept roughly equal. The participants were requested to rate each of the names for their AoA, familiarity, and facial distinctiveness by putting a line through the number corresponding to their chosen response. It was emphasized that their decisions should be made on facial features alone and that other physical characteristics, such as height and hair color, should be discounted.

Seven-point scales were employed on the familiarity and distinctiveness variables, in accordance with Moore (1998). However, to encompass the atypically wider age range than those used in most previous investigations, a 10-point scale was employed for the ratings of AoA.
Familiarity. The participants were asked to estimate how many times in their lifetime they had heard, seen, read about, or otherwise been reminded of each of the celebrities (from $1=$ unknown to $7=$ encountered extremely often). It was stressed that this should be an estimate of how many times, prior to the experiment, each celebrity had been encountered in the participants' personal daily life, on television, in films, newspapers, magazines, or posters, and so on.

Distinctiveness. The participants were asked to imagine how easy each celebrity would be to recognize from just his or her facial features (Valentine \& Bruce, 1986). The scale ranged from 1 = a typical, hardto-spot face to $7=$ a distinctive, easy-to-spot face. This was done on the basis of the image each participant had of the famous person in his or her mind's eye, rather than from a particular photograph.

AoA. The participants were requested to indicate how old they were when they had first become aware of each famous person. The AoA rating scale ran from $1=$ less than 5 years old, $2=$ less than $10,3=$ less than $15,4=$ less than 25 , and so on up to $10=$ less than 85 years old.

\section{Procedure}

The participants were asked to rate the names of famous people for their AoA, familiarity, and facial distinctiveness by marking the appropriate point on each of the scales.

A detachable, large print, rating key was provided in the mailout, to be used by the participants as they made their ratings. The returned sheets were coded, and means were calculated for each of the three factors.

\section{Additional Ratings}

Additional ratings were taken as post hoc controls on a number of experiments. Those tasks were also performed by the over-40s, following the same method as that described above.

\section{Results and Discussion}

The online database shows the breakdown of the ratings data into that provided by participants in their $40 \mathrm{~s}, 50 \mathrm{~s}$, $60 \mathrm{~s}, 70 \mathrm{~s}$, and $80 \mathrm{~s}$, as well as overall mean rating scores for each celebrity, collapsed across all the age groups. The rating scores were summed from the initial and additional ratings. A mean score was then calculated by dividing the

Table 3

Overall Descriptive Analyses for the Normative Data Appearing in the Database

\begin{tabular}{lrrc}
\hline & $M$ & \multicolumn{1}{c}{$S D$} & Range \\
\hline Surname frequency & 137.06 & 203.43 & $0.00-1152.00$ \\
Number of times generated & 34.11 & 30.32 & $6-171$ \\
Total number of phonemes & 9.88 & 2.26 & $4-20$ \\
40-year-old familiarity & 3.78 & 1.34 & $1.00-6.40$ \\
40-year-old distinctiveness & 3.55 & 1.36 & $1.00-6.00$ \\
40-year-old age of acquisition (AoA) & 3.71 & 1.18 & $1.00-6.33$ \\
50-year-old familiarity & 3.89 & 1.08 & $1.00-6.00$ \\
50-year-old distinctiveness & 3.67 & 1.20 & $1.00-5.88$ \\
50-year-old AoA & 4.55 & 1.36 & $1.38-8.00$ \\
60-year-old familiarity & 4.16 & 1.09 & $1.00-7.00$ \\
60-year-old distinctiveness & 3.87 & 1.22 & $1.00-6.00$ \\
60-year-old AoA & 5.21 & 1.59 & $1.50-8.00$ \\
70-year-old familiarity & 3.69 & 1.13 & $1.00-6.00$ \\
70-year-old distinctiveness & 3.47 & 1.30 & $1.00-6.00$ \\
70-year-old AoA & 6.07 & 1.73 & $1.50-9.25$ \\
80-year-old familiarity & 4.08 & 1.37 & $1.00-6.00$ \\
80-year-old distinctiveness & 3.69 & 1.33 & $1.00-6.00$ \\
80-year-old AoA & 6.52 & 1.94 & $1.00-10.00$ \\
Overall familiarity & 3.92 & 0.84 & $1.00-6.00$ \\
Overall distinctiveness & 3.67 & 1.00 & $1.26-5.88$ \\
Overall AoA & 5.03 & 1.39 & $2.05-7.88$ \\
\hline
\end{tabular}


summed totals by the total number of participants who provided ratings. The resulting mean scores are presented in the online database. Descriptive analyses for the normative data are shown in Table 3.

Bivariate (Pearson) correlations were run between surname frequency $(N=294)$, number of times generated, total number of phonemes, and overall mean ratings of familiarity, distinctiveness, and AoA $(N=696$ in all cases). Table 4 shows a comparison of correlations between variables known to influence face-processing speed with similar variables found to have an influence on object-processing speed in a number of studies. The correlational data will be discussed in relation to object processing. There were a number of significant correlations between the dependent variables. The number of times a name was generated correlated significantly with number of phonemes $(r=.102, p<.01)$, familiarity $(r=.317, p<.001)$, and distinctiveness $(r=.302$, $p<.001)$. There were also significant negative correlations between the number of times generated and AoA $(r=-.144, p<.001)$ and surname frequency $(r=$ $-.131, p<.05)$. It would appear from this that people are more likely to spontaneously remember famous people learned early in life than those acquired later. More unusual names resulted in more participants generating those celebrities. There was also a significant correlation between familiarity and distinctiveness $(r=.925, p<$ $.001)$. However, the relationship between the two variables was positive, rather than the negative correlation that would be predicted from studies of object processing. Ratings of distinctiveness and familiarity have been found to correlate highly in previous face-processing studies (e.g., Moore, 1998). The negative correlation between AoA and familiarity fell just short of significance $(r=-.067, p=.075)$. Early-acquired objects were also rated as more familiar than later-acquired items. There was no significant correlation between AoA and distinctiveness $(r=-.052, p=.173)$. The evidence from ob- ject processing is equivocal concerning this relationship, with some studies reporting a significant positive correlation between the two variables, whereas others have shown no such relationship.

\section{GENERAL DISCUSSION}

The data reported in this article will allow researchers to select stimuli that are highly familiar to a large proportion of adults from the general population. This will facilitate the ease with which the listed stimuli can be matched on a number of important attributes. The database provides ratings of AoA, familiarity, facial distinctiveness, surname frequency, and number of phonemes. The transience of fame means that some of the famous people recorded in this article may not be remembered in years to come (see, e.g., Rizzo et al., 2002). The individual frequency of encounter (or familiarity) for other stimuli may also change over time. For example, the death of Pope John Paul II (April 2005) will have increased his rated familiarity from the scores provided in the database taken prior to his death. However, such changes are actually beneficial to researchers specifically interested in frequency of encounter, since they allow before and after comparisons to be made.

The separate reporting of ratings by participants of different ages, in addition to the overall mean rating, will bestow greater longevity on the database as a useful research tool. This is particularly the case for studies of AoA for people. Furthermore, the fact that participants have been involved in generating the stimuli, rather than just being given a list of names to rate, should ensure that the database constitutes a representative and well-known sample of famous people from different decades. Finally, this database provides an accurate, a priori list of empirical measures on a number of attributes. Although many of these, such as phoneme length, remain the same, others, such as familiarity, may be more dynamic. It is therefore suggested that researchers using this tool would be well advised, where possible, to

Table 4

Comparison of Correlations Derived From the Celebrity Stimuli With Those From Object-Processing Studies

\begin{tabular}{lcccccccc}
\hline & Significance & A & BBDB & B & BME & H\&E & S\&V & S\&Y \\
\hline AoA-distinctiveness & $.173-$ & & & + & & & + & - \\
AoA-frequency & $.365+$ & - & - & - & - & & - & - \\
AoA-familiarity & $.075-$ & - & & - & - & - & - & - \\
AoA-word length & $.859-$ & + & + & + & + & + & & + \\
Distinctiveness-familiarity & $.925+$ & - & & - & - & - & - & - \\
Distinctiveness-frequency & $.108-$ & & & & - & - & - & \\
Distinctiveness-word length & $.680-$ & & & & + & & & + \\
Familiarity-frequency & $.141-$ & + & + & & + & + & & + \\
Familiarity-word length & $.529-$ & & & & - & - & & \\
Frequency-word length & $.594-$ & - & - & - & - & - & & - \\
\hline
\end{tabular}

Note-Where significant correlations emerged, this is denoted with either a + (a positive relationship) or a - (a negative relationship). Values of $p$ are also presented for the face data reported in this article. In the case of the object-processing studies, read visual complexity for distinctiveness. Word length includes measures of phonemes, letters, and syllables. A, Alario et al. (2004); BBDB, Bates, Burani, D'Amico, and Barca (2001); BME, Barry, Morrison, and Ellis (1997); B, Bonin, Chalard, Méot, and Fayol (2002); H\&E, Hodgson and Ellis (1998); S\&V, Snodgrass and Vanderwart (1980); S\&Y, Snodgrass and Yuditsky (1996). 
collect appropriate ratings post hoc, in order to control for individual differences and stimulus validation.

\section{REFERENCES}

Alario, F.-X., \& FERrand, L. (1999). A set of 400 pictures standardized for French: Norms for name agreement, image agreement, familiarity, visual complexity, image variability, and age of acquisition. Behavior Research Methods, Instruments, \& Computers, 31, 531-552.

Alario, F.-X., Ferrand, L., Laganaro, M., New, B., FrauenfeldER, U. H., \& SEgUI, J. (2004). Predictors of picture naming speed. Behavior Research Methods, Instruments, \& Computers, 36, 140-155.

BaAyen, H., Piepenbrock, R., \& van Rijn, H. (1993). The CELEX lexical database [CD-ROM]. Philadelphia: University of Pennsylvania, Linguistic Data Consortium.

Barca, L., Burani, C., \& Arduino, L. S. (2002). Word naming times and psycholinguistic norms for Italian nouns. Behavior Research Methods, Instruments, \& Computers, 34, 424-434.

Barry, C., Morrison, C. M., \& Ellis, A. W. (1997). Naming the Snodgrass and Vanderwart pictures: Effects of age of acquisition, frequency, and name agreement. Quarterly Journal of Experimental Psychology, 50A, 560-585.

Bates, E., Burani, C., D'Amico, S., \& Barca, L. (2001). Word reading and picture naming in Italian. Memory \& Cognition, 29, 986-999.

Bird, H., Franklin, S., \& Howard, D. (2001). Age of acquisition and imageability ratings for a large set of words, including verbs and function words. Behavior Research Methods, Instruments, \& Computers, 33, 73-79.

Bonin, P., Chalard, M., Méot, A., \& Fayol, M. (2002). The determinants of spoken and written picture naming latencies. British Journal of Psychology, 93, 89-114.

BrÉDART, S. (1993). Retrieval failures in face naming. Memory, 1, 351366.

Brysbaert, M., LAnge, M., \& VAN WiJnendaele, I. V. (2000). The effects of age-of-acquisition and frequency-of-occurrence in visual word recognition: Further evidence from the Dutch language. European Journal of Cognitive Psychology, 12, 65-85.

Carroll, J. B., \& White, M. N. (1973). Age-of-acquisition norms for 220 picturable nouns. Journal of Verbal Learning \& Verbal Behavior, 12, 563-576.

Coltheart, M. (1981). The MRC Psycholinguistic Database. Quarterly Journal of Experimental Psychology, 33A, 497-505.

Cortese, M. J., \& FugetT, A. (2004). Imageability ratings for 3,000 monosyllabic words. Behavior Research Methods, Instruments, \& Computers, 36, 384-387.

Cuetos, F., Ellis, A.W., \& Alvarez, B. (1999). Naming times for the Snodgrass and Vanderwart pictures in Spanish. Behavior Research Methods, Instruments, \& Computers, 31, 650-658.

Cycowicz, Y. M., Friedman, D., Rothstein, M., \& Snodgrass, J. G. (1997). Picture naming by young children: Norms for name agreement, familiarity, and visual complexity. Journal of Experimental Child Psychology, 65, 171-237.

Ferrand, L., \& New, B. (2003). Syllabic length effects in visual word recognition and naming. Acta Psychologica, 113, 167-183.

Gernsbacher, M. A. (1984). Resolving 20 years of inconsistent interactions between lexical familiarity and orthography, concreteness, and polysemy. Journal of Experimental Psychology: General, 113, 256-281.

Gilhooly, K. J., \& LogIE, R. H. (1980a). Age-of-acquisition, imagery, concreteness, familiarity, and ambiguity measures for 1,944 words. Behavior Research Methods \& Instrumentation, 12, 395-427.

Gilhooly, K. J., \& LogIe, R. H. (1980b). Meaning-dependent ratings of imagery, age of acquisition, familiarity, and concreteness for 387 ambiguous words. Behavior Research Methods \& Instrumentation, 12, 428-450.

Hodgson, C., \& Ellis, A. W. (1998). Last in, first to go: Age of acquisition and naming in the elderly. Brain \& Language, 64, 146-163.

Humphreys, G., RIDDOCH, M. J., \& Quinlan, P. T. (1988). Cascade processes in picture identification. Cognitive Neuropsychology, 5, 67-103.

Jones, D. (1997). English pronouncing dictionary (15th ed.). Cambridge: Cambridge University Press.

Klapp, S. T., Anderson, W. G., \& Berrian, R. W. (1973). Implicit speech in reading, reconsidered. Journal of Experimental Psychology, 100, 368-374.

LADEFoged, P. (1993). A course in phonetics (3rd ed.). Fort Worth, TX: Harcourt Brace Jovanovich.

LEWIS, M. B. (1999). Age of acquisition in face categorisation: Is there an instance-based account? Cognition, 71, B23-B39.

MAsterson, J., \& Druks, J. (1998). Description of a set of 164 nouns and 102 verbs matched for printed word frequency, familiarity and age-of-acquisition. Journal of Neurolinguistics, 11, 331-354.

Meyer, A. S., Roelofs, A. P. A., \& Levelt, W. J. M. (2003). Word length effects on object naming: Role of a response criterion. Journal of Memory \& Language, 48, 131-147.

Moore, V. M. (1998). The effects of age of acquisition in processing people's faces and names. Unpublished doctoral thesis, University of Durham.

Moore, V. [M.], Smith-Spark, J. H., \& Valentine, T. (2004). The effects of age of acquisition on object recognition. European Journal of Cognitive Psychology, 16, 417-439.

Moore, V. [M.], \& Valentine, T. (1993). Names count: An assessment of surname frequencies in North-West England. Unpublished database.

Moore, V. [M.], \& VAlEntine, T. (1998). The effect of age of acquisition on speed and accuracy of naming famous faces. Quarterly Journal of Experimental Psychology, 51A , 485-513.

Moore, V. [M.], \& VAlentine, T. (1999). The effects of age of acquisition in processing famous faces and names: Exploring the locus and proposing a mechanism. In M. Hahn \& S. C. Stoness (Eds.), Proceedings of the Twenty-First Annual Meeting of the Cognitive Science Society (pp. 416-421). Mahwah, NJ: Erlbaum.

Morrison, C. M., Chappell, T. D., \& Ellis, A. W. (1997). Age of acquisition norms for a large set of object names and their relation to adult estimates and other variables. Quarterly Journal of Experimental Psychology, 50A, 528-559.

Morrison, C. M., \& Ellis, A. W. (1995). The roles of word frequency and age of acquisition in word naming and lexical decision. Journal of Experimental Psychology: Learning, Memory, \& Cognition, 21, 116-133.

Morrison, C. M., Ellis, A. W., \& Quinlan, P. T. (1992). Age of acquisition, not word frequency, affects object naming, not object recognition. Memory \& Cognition, 20, 705-714.

Paivio, A., Yuille, J. D., \& Madigan, S. A. (1968). Concreteness, imagery, and meaningfulness values for 925 nouns. Journal of Experimental Psychology: Monograph Supplement, 76(1, Pt. 2), 1-25.

Pind, J., \& TryggVadótTir, H. B. (2002). Determinants of picture naming in Icelandic. Scandinavian Journal of Psychology, 43, 221-226.

Rendell, P. G., Castel, A. D., \& Craik, F. I. M. (2005). Memory for proper names in old age: A disproportionate impairment? Quarterly Journal of Experimental Psychology, 58A, 54-71.

Rizzo, S., Venneri, A., \& PAPAgno, C. (2002). Famous face recognition and naming test: A normative study. Neurological Sciences, 23, 153-159.

SARnO, J. A., \& Alley, T. R. (1997). Attractiveness and the memorability of faces: Only a matter of distinctiveness? American Journal of Psychology, 110, 81-92.

Snodgrass, J. G., \& Vanderwart, M. (1980). A standardized set of 260 pictures: Norms for name agreement, image agreement, familiarity, and visual complexity. Journal of Experimental Psychology: Human Learning \& Memory, 6, 174-215.

SnOdgrass, J. G., \& Yuditsky, T. (1996). Naming times for the Snodgrass and Vanderwart pictures. Behavior Research Methods, Instruments, \& Computers, 28, 516-536.

Sommer, W., Heinz, A., Leuthold, H., Matt, J., \& Schweinberger, S. R. (1995). Metamemory, distinctiveness, and event-related potentials in recognition memory for faces. Memory \& Cognition, 23, 1-11.

SpreEN, O., \& Schulz, R. W. (1966). Parameters of abstraction, meaningfulness, and pronunciability for 329 nouns. Journal of Verbal Learning \& Verbal Behavior, 5, 459-468.

Stuart, M., Dixon, M., Masterson, J., \& Gray, B. (2003). Children's early reading vocabulary: Description and word frequency lists. British Journal of Educational Psychology, 73, 585-598.

Szekely, A., Jacobsen, T., D’ Amico, S., Devescovi, A., Andonova, E., Herron, D., ET AL. (2004). A new on-line resource for psycholinguistic studies. Journal of Memory \& Language, 51, 247-250. 
Turner, J. E., Valentine, T., \& Ellis, A. W. (1998). Contrasting effects of age of acquisition and word frequency on auditory and visual lexical decision. Memory \& Cognition, 26, 1282-1291.

VALEnTine, T. (1991). A unified account of the effects of distinctiveness, inversion, and race in face recognition. Quarterly Journal of Experimental Psychology, 43A, 161-204.

Valentine, T., Brédart, S., LaWSon, R., \& Ward, G. (1991). What's in a name? Access to information from people's names. European Journal of Cognitive Psychology, 3, 147-176.

VALENTINe, T., BRENnen, T., \& BRÉDART, S. (1996). The cognitive psychology of proper names: On the importance of being Ernest. London: Routledge.

Valentine, T., \& Bruce, V. (1986). The effects of distinctiveness in recognising and classifying faces. Perception, 15, 525-535.

VAlentine, T., \& Moore, V. (1995). Naming faces: The effects of facial distinctiveness and surname frequency. Quarterly Journal of Experimental Psychology, 48A, 849-878.

Vitkovitch, M., \& TyrRell, L. (1995). Sources of disagreement in object naming. Quarterly Journal of Experimental Psychology, 48A, 822-848.

Zevin, J. D., \& SeIDEnBerg, M. S. (2002). Age of acquisition effects in word reading and other tasks. Journal of Memory \& Language, 47, 1-29.

\section{NOTES}

1. Familiarity is assumed to be equivalent to cumulative frequency, because it comprises measures of the experimental participants' estimates of how frequently an object or person has been encountered in their personal environment. For example, a fruiterer would estimate apple as more frequently encountered than would a furniture maker. Therefore, in this article, familiarity is more closely related to conceptual familiarity than to lexical subjective frequency.

2. But see Alario et al.'s (2004) review of object naming.

3. Since this is a list of norms intended primarily for use by British English speakers, the phoneme counts for foreign names, such as Brigitte Bardot, reflect an anglicized pronunciation, rather than the strict native pronunciation. There is some debate in the literature as to whether the sound at the beginning of church and that at the beginning of jean are best represented by one or two phonemes (see Ladefoged, 1993). Since the second component of each cluster occurs only in that setting, and not in other clusters, this article will treat them as a single phoneme. Finally, although it is commonly accepted that diphthongs are single phonemes, there is some debate concerning triphthongs. This article will treat triphthongs as two phonemes composed of an initial diphthong followed by a schwa.

4. Ronnie and Reggie Kray were included in the database because the Kray twins were generated by a total of 78 participants (although the individual brothers were generated by name only six times each).

5 . This number reflects the number of potential ratings, since some famous people may have been known to only a sample of these participants.

6. One participant's gender was omitted.

7. See note 6.

\section{ARCHIVED MATERIALS}

The following materials and links may be accessed through the Psychonomic Society's Norms, Stimuli, and Data Archive, www.psychonomic .org/archive. To access these files or links, search the archive for this article using the journal name (Behavior Research Methods), the first author's name (Smith-Spark), and the publication year (2006).

FILE: smith-spark-BRMIC-2006.zip

DESCRIPTION: The compressed archive file contains five files:

smith-spark2006database.pdf, containing the database of famous people developed by Smith-Spark, Moore, Valentine, and Sherman, as a 189K PDF file. Each row represents 1 of 696 famous people; each column, one of the dependent measures.

smith-spark2006database.rtf, containing the same database as a 3.58MB rich text format file. Again, each row represents 1 of 696 famous people; each column, one of the dependent measures.

smith-spark2006database.sav, containing the same database as a 108K SPSS data file.

smith-spark2006appendix.pdf, containing footnotes pertaining to items held in the database.

smith-spark2006appendix.rtf, containing footnotes pertaining to items held in the database.

AUTHOR’s E-MAIL ADDRESs: smithspj@1sbu.ac.uk

(Manuscript received April 28, 2005; revision accepted for publication July 19, 2005.) 